\title{
AST/ASTS Workshop on Increasing Organ Donation in the United States: Creating an "Arc of Change" From Removing Disincentives to Testing Incentives
}

\author{
D. R. Salomon ${ }^{1, *}$, A. N. Langnas ${ }^{2}$, A. I. Reed ${ }^{3}$, \\ R. D. Bloom ${ }^{4}$, J. C. Magee ${ }^{5}$ and R. S. Gaston ${ }^{6}$ \\ for the AST/ASTS Incentives Workshop Group \\ (IWG) $^{a}$ \\ ${ }^{1}$ Department of Molecular and Experimental Medicine, \\ The Scripps Research Institute, La Jolla, CA \\ ${ }^{2}$ Department of Surgery, University of Nebraska Medical \\ Center, Omaha, NE \\ ${ }^{3}$ Department of Surgery, University of lowa, lowa City, IA \\ ${ }^{4}$ Department of Medicine, University of Pennsylvania, \\ Philadelphia, PA \\ ${ }^{5}$ Department of Surgery, University of Michigan, \\ Ann Arbor, MI \\ ${ }^{6}$ Department of Medicine, University of Alabama, \\ Birmingham, $A L$ \\ *Corresponding author: Daniel R. Salomon, \\ dsalomon@scripps.edu \\ ${ }^{a}$ For a complete listing of the IWG members and \\ affiliations see Appendix.
}

The American Society of Transplantation (AST) and American Society of Transplant Surgeons (ASTS) convened a workshop on June 2-3, 2014, to explore increasing both living and deceased organ donation in the United States. Recent articles in the lay press on illegal organ sales and transplant tourism highlight the impact of the current black market in kidneys that accompanies the growing global organ shortage. We believe it important not to conflate the illegal market for organs, which we reject in the strongest possible terms, with the potential in the United States for concerted action to remove all remaining financial disincentives for donors and critically consider testing the impact and acceptability of incentives to increase organ availability in the United States. However, we do not support any trials of direct payments or valuable considerations to donors or families based on a process of market-assigned values of organs. This White Paper represents a summary by the authors of the deliberations of the Incentives Workshop Group and has been approved by both AST and ASTS Boards.

Abbreviations: AST, American Society of Transplantation; ASTS, American Society of Transplant Surgeons; CMS, Centers for Medicare and Medicaid Services; HRSA, Health Resources and Services Administration; IWG, Incentives Working Group; NLDAC, National Living Donor Assistance Center; NOTA, National Organ
Transplant Act; OPTN, Organ Procurement and Transplantation Network

Received 14 October 2014, revised and accepted for publication 16 January 2015

\section{Introduction}

It has been estimated that by 2015 over 700000 Americans will have end stage renal disease and over 26 million will have some form of chronic kidney disease; those are numbers that continue increasing (1). Kidney transplantation is the most effective therapy for kidney failure, the ultimate outcome for many with chronic kidney disease (2). Its benefits include significantly better quality of life, fewer medical complications, and longer survival; it is also substantially less costly than the only alternative, longterm dialysis. For healthcare in the United States, successful transplantation means savings of perhaps $\$ 10$ billion/year (approximately $\$ 55000 /$ year for the life of every functioning transplant).

Unfortunately, our current system of organ donation is not meeting the growing demand. The list of active patients waiting for kidney transplants is now over 75000, yet we will transplant less than 17000 this year (http://optn. transplant.hrsa.gov/data/). The average wait for a kidney transplant has risen to almost 5 years (much longer in some parts of the country); about 4000 patients die waiting on the list each year with more removed from the list because their health status has deteriorated to the point that they are too sick to withstand transplantation. Moreover, recent studies clearly demonstrate that the longer a patient is on dialysis before transplantation, the greater the risk of complications and death following transplant.

Recent articles in the lay press on illegal organ sales and transplant tourism $(3,4)$ highlight the impact of the current black market in kidneys that accompanies the global organ shortage. However, we believe it important not to conflate the illegal market for organs, which we reject in the strongest possible terms, with the potential in the United States for concerted action to remove all remaining financial disincentives for potential donors and critically consider 


\section{Salomon et al}

testing the impact and acceptability of incentives to increase organ availability in the United States.

\section{Rationale and Underlying Principles}

The potential for financial incentives to increase organ donation, and ethical considerations that might accompany their implementation remains a controversial topic, fraught with confusion and misunderstanding, and with global implications. Given the growing organ shortage and the evolving discussion of these issues, leadership of both the American Society of Transplantation (AST) and American Society of Transplant Surgeons (ASTS) agreed to convene a workshop to develop a policy statement, acceptable to both societies, on the potential of creating incentives for organ donation in the United States On June 2-3, 2014, 38 representatives of the two societies (including experts in medical ethics, economics, and health care law and policy) assembled in Chicago to explore the potential of incentives to increase both living and deceased organ donation. The organizers emphasized that defining a consensus on incentives in transplantation was beyond the scope of this workshop, and though the operational focus of the workshop was on kidney transplantation, principles developed should be applicable to other solid organs (i.e. heart, liver, lung) where incentivizing in the realm of deceased donors is a relevant consideration as well.

The Incentives Workshop Group (IWG) began with the premise that the AST and ASTS should have a shared approach for modifications in public policy regarding a topic as controversial as incentives in organ donation. This premise derived from conflicting articles in the medical literature and op-ed pages of major US publications that have repeatedly called attention to the limitations of the organ donation system in our country. Indeed, many economists and health policy experts have considered the growing waiting list as a failure of altruistic approaches to organ donation, promoting not only incentives but also various market-based solutions to remedy the problem $(5,6)$. Alternatively, others have raised concerns that, beyond ethical implications, any implementation of incentives based on the logic of markets and commodities could threaten the function and future of the altruistic system that is currently the foundation of organ donation (7). However, the organizers recognized that there remains a lack of real-world evidence at this time that market-based solutions would be effective or that concerns for damaging altruistic donation would be borne out. Thus, the Workshop did not begin with any assumption on whether incentives of any kind were good or bad policy. The AST and ASTS leadership agreed that the societies needed to consider all sides, the potential of change and construct a shared policy.

Another underlying premise was that deliberations would be limited to the context of what might be appropriate in the United States, independent of global considerations.
The AST and ASTS support the ethical underpinnings of the Declaration of Istanbul, as well as those of the more recent Doha Convention. We have the advantage in the United States of a well-developed system of altruistic living and deceased donor organ donation, stable government and rule of law, and a health system able to ensure autonomy of the individual. Thus, proper controls are in place to meet the requirements of the recent Manila statement regarding proposed standards for an acceptable system of incentives (8). There also appears to be sufficient awareness of the limitations of the current system, including morbidity and mortality on the waiting list, and willingness by the American public to consider new strategies in parallel to ongoing and strong support for the current altruistic system.

The Chicago meeting included plenary lectures on the history and current context of the debate on incentives in organ donation, economic rationales, ethical challenges, and the legal framework existing at both state and federal levels that must be considered in formulating any position and strategy. Five working groups with appropriately balanced expertise met separately to discuss the current landscape in the United States, possibilities and the challenges of incentives for living donation and deceased donors, the ethics and economics of incentives, and possible operational strategies for implementation. Working group summaries were then presented to the broader group for deliberations involving all attendees.

It is not the purpose of this report to detail the discussions nor the pros and cons presented. The ethical arguments on both sides of the issue are well documented in the literature, ranging from market-based approaches to impassioned defenses of a purely altruistic system (see Suggested Readings; [9-19]). The remainder of this article will briefly describe what the IWG discussed and then presented to the leadership of ASTS and AST as the basis of a shared approach for guiding modifications to public policy.

\section{An Arc of Change for Living Donors: Starting With Removing Disincentives to Living Donation}

The overarching theme that emerged from this Workshop was that challenges of considering any form of incentives for organ donation should be viewed as a series of decisions to be made along an "arc of change." This arc begins with optimization of the current system, but should proceed rapidly to identify and remove existing disincentives that impede the organ donation process. Removing disincentives should be the immediate priority.

The debate regarding implementation of any incentives is limited by vague semantics: one person's incentive (provision of health insurance for donors) is another's removal of disincentive (lack of consistent access to 
post-donation healthcare). In the near term, an operational process of removing disincentives would help define where the line now exists in the United States, and the potential impact of incentives to be better defined. Additionally, the line between incentives and removing disincentives must also be determined by existing medical practices, ethics, health policy and law including the National Organ Transplant Act passed by Congress in 1984 (20). This line would also be defined by the attitudes of the American public. Engaging the public in consideration of the potential of incentives to increase organ availability was recognized as an important task for both Societies. A shared statement on the current state of the field and the potential for incentives was considered a good start. Developing an operational plan together to address the challenges should follow.

The IWG considered a number of elements in the context of identifying and removing disincentives for living organ donation that potentially test where the line with providing incentives may lie. First, living donation is associated with financial costs to all donors. Furthermore, NOTA specifically states that donor reimbursement for travel, housing and lost wages does not fall under the prohibition of "valuable consideration" for an organ (42 USC 274e). While it is often assumed that expenses for living donors are fully reimbursable today, this is not the case. A major limitation is the lack of mechanisms and the necessary funding to accomplish the task of fully reimbursing donors for expenses allowable under NOTA. The ASTS, in collaboration with the University of Michigan (Drs. Akinlolu Ojo and Robert Merion) and the Health Resources Services Administration (HRSA), created the National Living Donor Assistance Center (NLDAC) in 2007 (https://www.livingdonorassistance.org; [21]). This resource processes submitted requests for reimbursements of justified costs and is highly effective. While participation in the program is limited (less than $10 \%$ of prospective beneficiaries participate), a survey of 493 donors that did participate found that approximately $75 \%$ (370) could not have donated without this support. The NLDAC process is also means-tested, requiring documentation that the donor or recipient has an income below a threshold set at $300 \%$ of the current poverty line. The IWG recognized that many potential donors with incomes significantly above the poverty line, even at the median national income of $\$ 50000$ per year, are still challenged to consider a major surgery and loss of income without support. The IWG agreed that continued efforts by both Societies are necessary to support and expand the mission and funding of the NLDAC, potentially enabling removal of means-testing and broader application so that no donor assumes financial risk in the process.

Beyond compensation of out of pocket travel expenses is reimbursement for lost wages. The IWG agreed that there is no substantial ethical impediment to such compensation. An issue that will require more discussion is whether such reimbursement should be linked to an income threshold, with a review process to determine the validity of individual requests. Some reasoned that on purely ethical grounds, if reimbursement of lost wages is appropriate then anyone should be eligible. Others took a pragmatic position that at some income level such reimbursement would be viewed as unnecessary in the context of the currently limited resources available. Continued efforts to have American businesses cover lost wages of employee-donors should also be supported through renewed efforts towards widespread adoption of the Family Leave Act (22). Operationally, the next step should involve an outreach to HRSA to determine if they would expand the current scope of NLDAC to include this function. The ultimate objective would be to expand NLDAC as a new public/private partnership of HRSA, private payers and both societies that could be the mechanism for evaluating and distributing different kinds of compensation to donors. This objective also recognizes and seeks the engagement of the many groups that are now stakeholders in the success of organ donation and transplantation in the United States.

Beyond that which is specifically permitted by NOTA, the IWG discussed other means that "might" be legally acceptable. It was suggested that a system where living donors that agreed to donate to strangers currently at the top of the waiting list would then have a lifetime "credit" to move a relative or loved one to the top of the list for a deceased donor organ later should it become necessary. Increasing living donation by making it possible for donors to invest in the future by providing expedited transplants for their families or closest friends that are not presently ready for transplantation, would also be the type of incentive that at a minimum would not increase costs to the system and may actually result in significant cost savings by transplanting higher risk patients more efficiently. The IWG considered this an appealing form of incentive. Being in-kind and noncommercial, it should not constitute a valuable consideration prohibited by NOTA. It would also be logical for the OPTN to implement and regulate. Preliminary data indicates that this system of reciprocity in Israel, also referred to as "reciprocal altruism" $(4,23)$ has been temporally associated with increased rates of deceased donor registration and transplantation. Moreover, the recent changes to Israel's laws included removal of certain disincentives for living donation that also enhanced donation rates.

An important disincentive is the potential for long-term donor health risk; one now generally accepted as requiring follow-up medical care for life. The IWG discussed the importance of mitigating lifetime risk of kidney disease in donors by increasing access to health insurance and medical care. In many countries with universal health insurance, this is not a major issue. But it is a very significant one for the US. Beyond simple lack of coverage, and even in the face of the provisions of the new Affordable Care Act, there remain costs involved in maintaining health insurance and limitations in what different policies cover in terms of health maintenance. Though many donors are covered by 


\section{Salomon et al}

their own insurance, the Societies should initiate discussions with private commercial payers to ensure monitoring and treatment of end stage organ disease and transplantation if necessary. Might lifetime insurance coverage cross the line from removing a disincentive to an overt incentive? The IWG noted that the Declaration of Istanbul implies such coverage as an essential part of an ethical living donor program. Would such an increase in the total cost of organ transplantation be viewed as justified or sustainable to critics? Arguments were considered on the high costs of treating end stage organ failure to the United States health care enterprise and the significant savings achieved with successful transplants. Therefore, the IWG supported the investigation of different models of providing or supplementing donor health insurance, with consideration of how this could be supported, financed and extended successfully. Possibilities discussed included tax incentives, public/private partnerships with $\mathrm{CMS}$ and payers and even philanthropic efforts.

The IWG also discussed the potential of compensation for dislocation from family in cases where donors travel to distant centers and the potential for consideration due to discomfort and pain from organ donation surgery. It was noted that courts and juries in cases of alleged injuries, malpractice and faulty products already consider these elements in settlement decisions. Finally, the IWG discussed potential compensation for direct risks involved in living organ donation including exposures to iodine dyes, radiation, anesthesia, and various drugs as well as indirect risks such as limitations on future employment due to having a single kidney. Further compensation for increased risks secondary to the increase risks for developing kidney disease in the future, such as younger donors that would simply live longer with a single organ, might develop obesity or diabetes only much later in life linked to familial risk factors or changing social circumstances that cannot be foreseen or potentially increased risks in people of African dissent were also discussed. While there was agreement that these are all legitimate risks of organ donation, the IWG realized that actual practice of providing compensation for these recognized risks would probably cross the line from removing disincentives to consideration of incentives.

\section{An Arc of Change for Living Donors: Exploring Incentives}

By the end of the meeting, it was agreed that though donors assume medical risk and, in most cases, the financial costs associated with donation, everyone else involved in the organ transplant process (recipients, physicians, hospitals, and associated professionals) benefits, most often financially. Might changing this dynamic encourage more potential donors to become actual donors? Thus, the IWG considered whether some kind of payments might be made to donors as honorariums. But the IWG realized that the challenge would be to determine how compensation for such risks could be operationalized. Simply paying out money to donors based on some schedule of increasing risks was unlikely to be acceptable at this time and the legal framework for such a practice is uncertain. However, starting the process of establishing a consensus on the relative risks of living donation was considered to be a good first step and consistent with the growing imperatives to optimize the safety of living organ donation.

Might the process be as simple as direct payment to donors? The IWG voiced no support for direct payment from recipients to donors. However, it may not be unreasonable to consider third party payments administered to living donors by a regulated entity with recovered organs allocated according to waiting list priority. The IWG concluded that such a move would represent a significant change in the practices of the current field that would require the understanding and buy-in of our patients, families and the American public.

However, there was no a priori reason not to work forward along the arc of change described above toward a plan for pilot projects in offering incentives now. Such pilot projects must be designed to test specific assumptions on the impact and efficacy of innovative ways to increase organ donation in real clinical practice. Legal opinion on how this would work within NOTA remains unknown and will require additional consultations with legal and public policy experts. However, if necessary to support pilot projects now, changing or modifying NOTA as a partnership with congressional partners should not be viewed as an insurmountable problem but rather as a worthy effort by both societies. As part of this process, we also need to closely track the evolution of attitudes among our fellow professionals, ethicists, patients and the American public that would be expressed in terms like repugnance and by ethical and possibly legal objections. Ultimately, the extent to which disincentives are removed and incentives are implemented will be dependent upon society's comfort as we traverse the "arc of change."

\section{Incentives in Deceased Organ Donation}

The challenges of offering incentives to increase organ donation from deceased donors were also considered in detail. The IWG recognized that the legal interpretation of NOTA was going to be a critical issue and specifically how to interpret the term "valuable consideration" for donation of an organ that is specifically prohibited in the legislation. The IWG also felt that sensitivity to the scope and definition of NOTA regulations would be consistently greater for deceased donors and that is the primary reason for more attention given here to the above discussions of moving along the arc of change in living donation.

A key point is that deceased donation represents a practice where the families are not directly benefiting from the 
increased health and productivity of the organ recipients that is clearly gained by their "gift." The IWG did not want to propose anything that might interfere with the spirit of altruism at the core of our nation's deceased donation system. Concerns were raised and discussed on the potential damage that might result from trying to negotiate the value of a donated organ. Thus, there was agreement that simple cash payments or equally direct forms of monetary compensation are prohibited by NOTA and the term, valuable consideration and were not desirable. However, we recognized that certain costs specifically added for deceased organ donation might fall outside of "valuable consideration" and be acceptable. We also recognized that several such proposals have been described and discussed over the years as a foundation. These include payments of certain hospital costs related to donation, as well as coverage of any costs that the organ donation process might impose on the families such as increased funeral costs. These might even be considered under the heading of removing disincentives and not adding incentives.

But the IWG also entered into frank discussions of what kind of monetary value could be placed on a deceased donor organ and how that could be justified by market principles as having meaningful impact on changing the success of the current organ donation system. These discussions involved several noted economists who explained the contrasts working in a free market between the supply of goods and services based on costs and demands. If the organ is supposed to be given away free to the benefit of others in the setting of high demand and limited supply, the market has little incentive to increase supply. The IWG also considered that there were ample precedents in the economic and legal fields that could be used to determine an organ's value if that was now considered desirable by the field. Thus, the IWG agreed that we should initiate the discussions with congressional leaders and health law experts to better understand what is possible now within the language of NOTA. However, as with living donation, it was also agreed that we need to learn what might be possible with a purposeful revision of NOTA to address these issues and potentially increase deceased organ donation. This better understanding will contribute to further discussions of the potential for pilot projects of incentives for deceased organ donation. However, it must be emphasized again that the IWG felt that proposing any changes that could negatively impact our current altruistic deceased donation system would continue to be very sensitive, any unintended negative impacts must be prevented and any steps in this direction would require much more discussion in the field.

\section{A Path Forward}

In conclusion, the IWG agreed that there was an actionable arc of change that could be initiated in the context of addressing the current challenges resulting from the organ shortage. This arc must start with a renewed focus to fully utilize the current legal framework and remove disincentives for organ donation, both living and deceased. The principle aim should be that those donating organs for transplantation should not be subjected to a financial penalty in addition to donation. This work should include assuring that processes like NLDAC are optimized, expanded beyond current financial constraints and positioned for the future. Expanding NLDAC into a public/private partnership would be a mechanism of expanding the available resources and provide a means to reimburse allowable expenses for all donors. That expansion should be discussed with HRSA and other stakeholders in organ transplantation including the commercial payers that also benefit greatly from successful transplants. Moving further along the "arc of change," any innovation will demand attention to differentiating between removal of a disincentive versus providing an incentive. It is often uncertain and will require an iterative process to constructively explore tactics and processes that will enhance organ availability for those in need, while staying within a legal and ethical framework. Which of our current assumptions are true, what innovations will be effective, what unintended consequences (including impacts internationally) will be realized and what will ultimately be acceptable in legal, ethical, and personal terms? Answering these questions should be the purpose of well-designed and critically reviewed pilot projects. However, it is also important to note that the IWG did not at this point support any trials of direct payments or valuable considerations to donors or donor families based on any process of market-assigned values of organs.

The IWG understood that the Workshop represented only a small group of leaders selected from the AST and ASTS, complemented by a few experts in economics, ethics and law; it was not a consensus process. The premise remains that the Societies need to have and operationalize a shared approach for guiding changes to public policies to impact the organ shortage, with a process in place to remain in step with the evolution of medical, ethical, and public discourse regarding a potential role for incentives. This White Paper is intended to report multiple approaches considered by the IWG to inform the members of both societies. The final shared approach to guiding changes in policy will necessarily be the work product of the AST and ASTS Boards. Consensus on such a shared approach will then require a deliberate effort to engage the many different stakeholders, consider their views, and refine our positions and our plans. During that consensus-making process, we should be working together along the arc of change to remove remaining disincentives, explore opportunities to either change or modify NOTA, and lay the groundwork for the next steps with our professional colleagues, experts in economics, law and ethics, our partners in Congress and agencies responsible for US health policy and the American public. 


\section{Salomon et al}

\section{Disclosure}

The authors of this manuscript have no conflicts of interest to disclose as described by the American Journal of Transplantation.

\section{References}

1. Gilbertson DT, Liu J, Xue JL, et al. Projecting the number of patients with end-stage renal disease in the United States to the year 2015. J Am Soc Nephrol 2005; 16: 3736-3741.

2. Wolfe RA, Ashby VB, Milford EL, et al. Comparison of mortality in all patients on dialysis, patients on dialysis awaiting transplantation, and recipients of a first cadaveric transplant. N Engl J Med 1999; 341: 1725-1730.

3. Sack K. Transplant brokers in Israel lure desperate kidney patients to Costa Rica. New York Times 2014.

4. Sack K. A clash of religion and bioethics complicates organ donation in Israel. New York Times 2014.

5. Satel S. Why people don't donate their kidneys. New York Times 2014.

6. Becker GS. Elias JJ. Cash for kidneys: The case for a market of organs. Wall Street Journal 2014.

7. Hippen BE, Satel S. Crowding out, crowding in, and financial incentives for organ procurement. In: Satel S, edditor. When altruism isn't enough. AEI Press, 2009.

8. Working Group on Incentives for Living D, Matas AJ, Satel S, et al. Incentives for organ donation: Proposed standards for an internationally acceptable system. Am J Transplant 2012; 12(2): 306-312.

9. Statement on the prohibition of any form of commercialization of human organs. Committee on Bioethics (DH-BIO), 5th Meeting; 2014 May; Strasbourg, France.

10. Arnold R, Bartlett S, Bernat J, et al. Financial incentives for cadaver organ donation: An ethical reappraisal. Transplantation 2002; 73: 1361-1367.

11. Barnieh L, Klarenbach S, Gill JS, Caulfield T, Manns B. Attitudes toward strategies to increase organ donation: Views of the general public and health professionals. Clin J Am Soc Nephrol 2012; 7 : 1956-1963.
12. Becker GS, Elias JJ. Introducing incentives in the market for live and cadaveric organ donations. J Econ Perspect 2007; 21: 3-24.

13. Chandler JA, Burkell JA, Shemie SD. Priority in organ allocation to previously registered donors: Public perceptions of the fairness and effectiveness of priority systems. Prog Transplant 2012; 22: 413-422.

14. Danovitch GM, Chapman J, Capron AM, et al. Organ trafficking and transplant tourism: The role of global professional ethical standards-The 2008 Declaration of Istanbul. Transplantation 2013; 95: 1306-1312.

15. Roberts R, Epstein R. The economics of organ donations. Econtalk, Library of Economics and Liberty. Indianapolis, IN: Liberty Fund; 2006.

16. The declaration of Istanbul on organ trafficking and transplant tourism. International Summit on Transplant Tourism and Trafficking, Istanbul, Turkey; 2008. Available from: www. declarationofistanbul.org.

17. Rodrigue JR, Crist K, Roberts JP, Freeman RB Jr., Merion RM, Reed Al. Stimulus for organ donation: A survey of the American Society of Transplant Surgeons membership. Am J Transplant 2009; 9: 2172-2176.

18. Roth AE. Repugnance as a constraint on markets. J Econ Perspect 2007; 21

19. Wellington AJ, Sayre EA. An evaluation of financial incentive policies for organ donations in the United States. Contemp Econ Policy 2011; 29: 1-13.

20. United States. National Organ Transplant Act: Public Law 98-507. United States Statutes at Large. 1984; 98: 2339-2348.

21. Warren PH, Gifford KA, Hong BA, Merion RM, Ojo AO. Development of the National Living Donor Assistance Center: Reducing financial disincentives to living organ donation. Prog Transplant 2014; 24: 76-81.

22. U.S. Department of Labor's Wage and Hour Division. The Family and Medical Leave Act. Final rule. Federal Register. 2013; 78: 8833-8947.

23. Lavee J, Ashkenazi T, Stoler A, Cohen J, Beyar R. Preliminary marked increase in the national organ donation rate in Israel following implementation of a new organ transplantation law. Am J Transplant 2013; 13: 780-785. 


\section{Appendix}

\begin{tabular}{|c|c|c|c|}
\hline \multicolumn{4}{|c|}{ Incentives Workshop Group (IWG) } \\
\hline Abecassis & Michael & $M D, M B A$ & Northwestern University, Feinberg School of Medicine \\
\hline Allan & James & $\mathrm{MD}$ & Massachusetts General Hospital \\
\hline Anderson & Rebecca & JD, MS & University of Nebraska \\
\hline Andreoni & Kenneth & MD & University of Florida \\
\hline Bloom & Roy & $\mathrm{MD}$ & University of Pennsylvania \\
\hline Cohen & David & $\mathrm{MD}$ & NY Presbyterian, Columbia University \\
\hline Cole & Edward & $\mathrm{MD}, \mathrm{FRCP}$ & University Health Network, University of Toronto \\
\hline Epstein & Richard & LL.B. & New York University Law School \\
\hline Fisher & Jonathan & $\mathrm{MD}$ & Scripps Green Hospital, Center for Organ Transplantation \\
\hline Frader & Joel & $\mathrm{MD}, \mathrm{MA}$ & Lurie Children's Hospital, Northwestern University Feinberg School of Medicine \\
\hline Freise & Chris & $\mathrm{MD}$ & University of California, San Francisco \\
\hline Friedewald & John & $\mathrm{MD}$ & Northwestern University, Feinberg School of Medicine \\
\hline Gaston & Robert & MD & University of Alabama, Birmingham \\
\hline Gill & John & MD & University of British Columbia \\
\hline Goldberg & David & MD, MSCE & University of Pennsylvania \\
\hline Gordon & Elisa & $\mathrm{PhD}, \mathrm{MPH}$ & Northwestern University, Feinberg School of Medicine \\
\hline Ham & John & MD & University of Nevada \\
\hline Ibrahim & Hassan & $M D, M S$ & University of Minnesota \\
\hline Krawiec & Kimberly & JD & Georgetown University \\
\hline Langnas & Alan & DO & University of Nebraska \\
\hline Levy & Gary & $\mathrm{MD}$ & University of Toronto \\
\hline Magee & John & $\mathrm{MD}$ & University of Michigan \\
\hline Matas & Arthur & $\mathrm{MD}$ & University of Minnesota \\
\hline Miller & Charles & $\mathrm{MD}$ & Cleveland Clinic Foundation \\
\hline Morrison & Joshua & $\mathrm{MD}$ & Alliance for Paired Donation \\
\hline Newell & Kenneth & $\mathrm{MD}, \mathrm{PhD}$ & Emory University \\
\hline Olthoff & Kim & $\mathrm{MD}$ & University of Pennsylvania \\
\hline Pruett & Timothy & $\mathrm{MD}$ & University of Minnesota \\
\hline Reed & Alan & $\mathrm{MD}, \mathrm{MBA}$ & University of lowa \\
\hline Rees & Michael & $\mathrm{MD}, \mathrm{PhD}$ & University of Toledo \\
\hline Reich & David & $\mathrm{MD}$ & Drexel University College of Medicine \\
\hline Rorick & Chris & MPA & AST Government Relations \\
\hline Roth & Alvin & $\mathrm{PhD}$ & Stanford University \\
\hline Salomon & Daniel & MD & The Scripps Research Institute \\
\hline Stock & Peter & $\mathrm{MD}, \mathrm{PhD}$ & University of California San Francisco \\
\hline Taylor & James & $\mathrm{PhD}$ & The College of New Jersey \\
\hline Tighe & Peggy & $\mathrm{JD}$ & Powers, Pyles, Sutter \& Verville PC \\
\hline Woodrum & $\mathrm{Jim}$ & MBA & Kellogg School of Management \\
\hline
\end{tabular}

